\title{
Redesigning an education project for child friendly radio: a multisectoral collaboration to promote children's health, education, and human rights after a humanitarian crisis in Sierra Leone
}

\author{
Sarah Barnett and colleagues describe how an educational project was rapidly adapted into a \\ radio education programme after the 2014 Ebola epidemic in Sierra Leone
}

I n May 2014, Sierra Leone reported its first case of Ebola in Kailahun, a remote, marginalised, and impoverished district bordering Liberia. ${ }^{1}$ The district had one of the highest concentrations of Ebola infections during this outbreak. ${ }^{2}$ After this, over 1600 children were orphaned ${ }^{3}$ and gender inequalities were exacerbated (box 1). Public health control measures put in place by the government of Sierra Leone included closing all schools and prohibiting public congregation.

The educational programme "Getting Ready for School”, funded by the UK charity Comic Relief, had been operating since its launch in 2011 within 21 schools in Kailahun. While many other educational services stopped entirely in Kailahun, the Getting Ready for School programme was redesigned as a radio education programme called Pikin to Pikin Tok (PtPT), meaning Child to Child Talk, in Krio. The lead consortium partner was Child to Child, a UK based international child rights non-governmental organisation (NGO)

\section{REY MESSAGES}

- A school based educational intervention in a remote district of Sierra Leone was reconfigured into a radio education programme, Pikin to Pikin Tok, during the Ebola outbreak in Sierra Leone

- Project success built on existing relationships with communities and government

- Continuous and open consultation with stakeholders, and adapting and evolving in response to feedback, contributed to achieving project goals

- Community ownership and participation were central to the collaboration, keeping children at its heart (www.childtochild.org.uk), and the lead implementing partner was Pikin-To-Pikin (www.pikintopikin.org), a local NGO. The goals and objectives of the project changed in response to the circumstances in Sierra Leone (table 1); this required a substantially different approach by the redesigned scheme (box 2) than in the original project (see suppl 1 on bmj.com). The entire effort, from starting the school project to the end of the radio project, ran from 2011 to 2016 (see suppl 2 on bmj.com).

To implement Getting Ready for Schools, Pikin-To-Pikin collaborated with the government Ministries of Education and Social Welfare, Gender and Children's Affairs, and with community representatives, including women's leaders, religious leaders, Kailahun's paramount or district chief, parents, and children. To enable PtPT to be designed and introduced, the collaboration was subsequently expanded to include the Ministry of Health and Sanitation, and the private sector. Additionally, it commissioned a local community radio station and international radio producers, and international child development experts (fig 1).
To evaluate the success of PtPT, and to understand the factors influencing successful collaboration, we used a general case study methods guide developed by the Partnership for Maternal, Newborn, and Child Health. ${ }^{9}{ }^{10}$ Specific methods were used for this case study. They included a review of project documentation, multistakeholder working group meetings in the country, consultations with key informants, a higher level multistakeholder dialogue meeting in Freetown, Sierra Leone, and a technical expert meeting in London with the Child to Child international advisers (methods described in suppl 3 on bmj.com).

\section{Key achievements and impact of PtPT}

Despite the Ebola outbreak, access to education was maintained through child led radio broadcasts. PtPT is known to have reached an audience of 136678 people (including children, parents, and teachers), more than originally targeted. The actual number reached may have been higher. Radio Moa broadcasts to a population of over 500000 in Kailahun, with listeners from other regions known to tune in. The circumstances surrounding

Box 1: Challenges facing children in Kailahun district, before and after the Ebola outbreak

- After Sierra Leone's civil war (1991-2002), Kailahun had the highest crime rate in the country. Early marriage, teenage pregnancy, sexual abuse, and other forms of violence became accepted as the norm; there was a lack of understanding of fundamental human rights

- Children, especially girls, faced many challenges that violated their rights and impeded their development

- The Ebola outbreak further eroded the fabric of society, and caused the collapse of government services. ${ }^{4}$ Women and girls were among the most vulnerable, with the outbreak exacerbating entrenched gender inequalities. For example, older girls often took on parental roles owing to the death of caregivers, which resulted in them dropping out of school $^{5}$

- Physical and sexual violence against girls increased and there was a substantial rise in teenage pregnancy rates, ${ }^{67}$ often linked to transactional sex to secure basic goods and services $^{7}$ 


\begin{tabular}{|c|c|c|}
\hline & Getting Ready for School (before Ebola) & Pikin to Pikin Tok (after Ebola) \\
\hline Goal & $\begin{array}{l}\text { Increase punctual school enrolment, academic performance, and } \\
\text { retention among children aged } 4-12 \text { years }\end{array}$ & $\begin{array}{l}\text { Enable young people aged } 4-8 \text { years to continue education, develop core } \\
\text { academic competencies, and play a role in transforming their communities in the } \\
\text { aftermath of the Ebola outbreak }\end{array}$ \\
\hline \multirow[t]{5}{*}{ Objectives } & Improve school readiness among children aged 4-8 years & $\begin{array}{l}\text { Equip 4-6 year olds with numeracy and literacy skills in preparation for starting } \\
\text { school, and improve hygiene practices }\end{array}$ \\
\hline & $\begin{array}{l}\text { Support children aged } 10-12 \text { years to improve academic performance } \\
\text { by building confidence and self esteem }\end{array}$ & $\begin{array}{l}\text { Support 7-12 year olds to improve literacy skills, hygiene practices, and to } \\
\text { develop life skills }\end{array}$ \\
\hline & $\begin{array}{l}\text { Increase knowledge of life skills and teenage awareness of concerns } \\
\text { such as child protection, pregnancy, and HIV/AIDS among children } \\
\text { aged } 10-12 \text { years }\end{array}$ & $\begin{array}{l}\text { Increase awareness among 12-18 year olds of teenage pregnancy, HIV, and child } \\
\text { protection, develop life skills, literacy skills, and hygiene practices }\end{array}$ \\
\hline & $\begin{array}{l}\text { Improve families' readiness to support education; promote positive } \\
\text { attitudes towards education and willingness to participate in children's } \\
\text { early learning and development }\end{array}$ & $\begin{array}{l}\text { Raise awareness among parents of the importance of positive parenting, parent- } \\
\text { child interactions, early childhood development, and continuing education for } \\
\text { older children }\end{array}$ \\
\hline & $\begin{array}{l}\text { Ensure schools are ready to receive and engage children and provide } \\
\text { child friendly environments that advance and promote learning }\end{array}$ & $\begin{array}{l}\text { Raise awareness among teachers of the problems that children in the community } \\
\text { are facing and the importance of child friendly teaching methods }\end{array}$ \\
\hline
\end{tabular}

the project meant that it was not prospectively evaluated. Much of the evidence for its influence comes from an endline evaluation by the Institute of Development, which was commissioned in 2016, ${ }^{11}$ and from a United Nations Girls' Education Initiative case study. ${ }^{5}$ Qualitative key informant interviews with programme beneficiaries were carried out at the endline evaluation. ${ }^{11}$ Box 3 illustrates the key findings from this evaluation. After the project ended in $2016,88 \%$ of community sensitisation committees remained active, and continued to convince parents of the importance of education. ${ }^{11}$

Gender was taken into account in the design, content, and broadcasting of the radio programmes (box 4). Clearly, no single programme, let alone one that focuses only on the demand side, is ever going to solve intractable challenges, such as ensuring girls' safety and upholding their rights to sexual and reproductive services. However, projects such as PtPT can work towards change. They can target harmful societal norms and enable citizens to hold policy makers accountable for improving access to high quality services in health, education, child protection, and sanitation.

The work done by PtPT in maintaining children's access to education during the Ebola outbreak, and tackling Sierra Leone's gender and child protection challenges, has received global recognition (box 5).

PtPT was an important catalyst for new programmes and relationships. The collaboration that delivered PtPT led to longer term relationships between PikinTo-Pikin and stakeholders in several sectors. For example, Pikin-To-Pikin now has representatives on national committees, participates in the Ministry of Education's new education strategy, and is implementing various projects for the Ministry of Health.
Although PtPT ended in 2016, its participatory and child friendly approach can be replicated and scaled up for use in other settings. For example, Radio Moa, encouraged by PtPT's success, continues to encourage child participation in radio broadcasts and invite children to voice their views. Similarly, the Roméo Dallaire Child Soldiers Initiative (https://www. childsoldiers.org) commissioned Child to Child, in partnership with Pikin-To-Pikin and former child soldiers, to develop a range of teaching resources to educate children about the risks of becoming a child soldier. Complementary materials to alert parents and teachers to their safeguarding responsibilities were also developed. Pikin-To-Pikin works with the initiative to disseminate these materials in schools, through the establishment of peace clubs. The project is being expanded by Pikin-ToPikin to incorporate a radio component, with audio recordings collected from communities, and child listening groups supplied with solar powered radios. The new project, not involving international partners, costs less than PtPT, and is more sustainable and scalable.

Building on the success of PtPT, Child to Child was commissioned by Unicef Sierra Leone to develop a new radio series, Fambul Tok (Family Talk) in Krio, with funding from the Open Society Foundation's early learning programme. Fambul Tok promotes awareness of early childhood development through radio programmes. These are designed to interest parents and caregivers in subjects relating to the optimal development of infants and young children (eg, breastfeeding, talking to, and playing with, babies). To increase their accessibility, the programmes feature people in communities across Sierra Leone, and a humorous soap opera portrays a husband and wife exploring how best to raise their infant.

\section{Key contributing factors to a successful collaboration}

Sustained commitment and flexibility from all partners, during and after the crisis

"Pikin-To-Pikin wanted to react, while others were paralysed by fear. No one knew what to do, it needed cour-

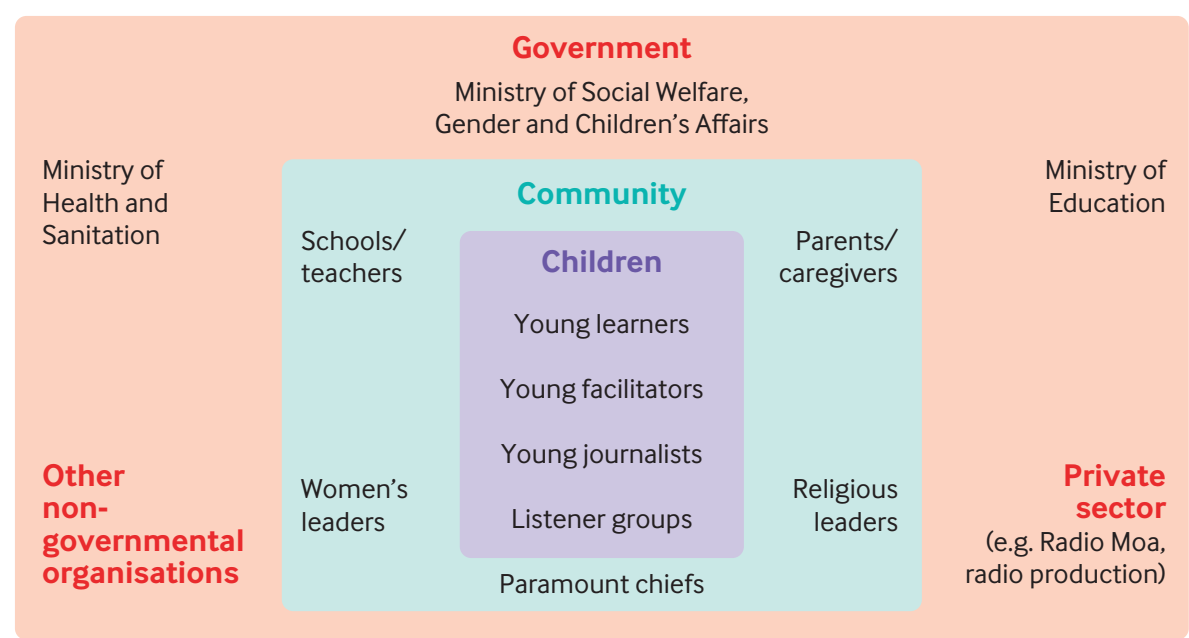

Fig 1 | Key stakeholders who worked with PtPT 
age to respond, and a consultative process to ensure the response was appropriate."Former international grants programme manager: Education, Comic Relief, June 2018

The Getting Ready for School project was funded by a $€ 1.2$ million ( $€ 1.3 \mathrm{~m}, \$ 1.6 \mathrm{~m}$ ) grant spread over 5 years. When the scale of the Ebola outbreak became apparent, Comic Relief recognised the need for flexibility in order to continue supporting those affected. They stated that among their education grantees operating within Sierra Leone, Pikin-To-Pikin was the only organisation that remained operational, adapting their activities in response to the crisis.

Throughout the Ebola outbreak, Pikin-ToPikin supported vulnerable communities, and participated in emergency relief work. Resources were made available to enable the NGO to procure emergency response materials (eg, chlorine for disinfection, buckets for hand washing, surgical gloves, megaphones, and rain boots), which were donated to the Ministry of Health, through the district health management team in Kailahun. Pikin-To-Pikin supported the distribution of the materials and training on the use of protective equipment. This strengthened their existing relationship with the Ministry of Health from initiatives before Getting Ready for School. The donor's willingness to adapt its funding requirements enabled Pikin-To-Pikin to consult communities and government to identify local priorities, reinforcing its existing relationships with community and religious leaders, and fostering trust and community support when PtPT was launched.

Comic Relief appreciated the frequency and transparency with which Child to Child involved them in discussions about how to continue supporting the affected communities. Child to Child kept the donor informed of the rapidly changing needs of the community. The donor allowed frequent budget changes to respond to these needs. It adapted its monitoring, evaluation, and due diligence requirements while ensuring that the NGO continued to provide accountability for the grant funding.

Adaptability in response to changing contexts The NGOs collaborated with a UK production team to develop the radio programmes featuring a Sierra Leonean story teller, Usifu Jalloh. Traditional stories were adapted to incorporate messages about behavioural change, with local music used to increase appeal. PtPT, which first broadcast immediately after the epidemic, instantly became popular with a cross generational audience. The stories encouraged children to reflect on their own concerns and to share their stories. As schools were closed for the year 201415 , PtPT programmes included literacy and numeracy.

The government also broadcast a national education programme in this period, with a key difference being that PtPT focused on co-creating local content with children affected by Ebola. These children, undoubtedly among the most vulnerable

\section{Box 2: Main components of Pikin to Pikin Tok (after Ebola)}

\section{Young journalists}

Thirty six children affected by the Ebola crisis ( 21 girls, 15 boys) had been young facilitators in the original programme. They worked alongside Pikin-To-Pikin's field staff to develop the radio programmes, by conducting interviews, making recordings for the programmes, and ensuring the project remained child centred

\section{Radio programmes broadcast by Radio Moa}

The children's programmes were trilingual-narrated in English, Krio (the common language in Sierra Leone) and Kissi (the predominant language in the project area). Distinct strands were presented, tailored to the needs and capabilities of each of the three age groups, using different methods of relaying information:

- Story time (targeting 4-6 year olds), to increase self esteem and numeracy and literacy skills through the power of storytelling

- Messages through music (targeting 7-12 year olds), to share lifesaving health and hygiene messages-for example, the importance of hand washing to prevent contagion

- Under the Mango Tree programme (targeting 12-18 year olds), which dealt directly with developing problems related to Ebola, such as stigma, social exclusion, disability, and sexual violence. The programmes promoted skills for coping with difficult circumstances requiring care and support, including bereavement. They also targeted parents with messages about positive parenting, parent-child interactions, and the importance of education

\section{Radio distribution}

Wind up, solar powered radios were distributed to each of 252 listening group facilitators, and 21 large MP3 radios were distributed to teachers in the 21 original project schools. Child to Child trained the facilitators (mostly school teachers involved in the original project) to use the radios, for which each of them was responsible

\section{Listening groups}

Listening groups were established, in which children listened to the radio programmes and discussed topics raised, supported by a trained facilitator. Facilitators were also trained to encourage young listeners to assemble during broadcasts, in how to assist discussion among young listeners, and in basic child protection. Forty two facilitators of formal listening groups were paid and were responsible for meeting a group of 10-25 children four times a week during the broadcasts (after prohibitions against group meetings had been lifted). Nearly 630 children, with similar numbers of boys and girls, most aged 7-12, took part in formal listening groups. The 210 facilitators of informal listening groups were not paid, and formation of these groups depended on the interest of the facilitator and children in the community. Once schools were opened some teachers used the radio programmes in their lessons

Phone in and panel discussions after the broadcast

A phone in and panel discussion followed each broadcast. Multilingual (Kissi, Mende, Krio, and English) call in sessions allowed personal interaction between expert panellists (eg, government representatives, a psychiatric nurse, a member of a local women's empowerment organisation), project implementers, children, and parents. The panellists answered questions, provided advice, and gave encouragement for coping with the crisis 
Box 3: Key findings from endline evaluation and United Nations Girls' Education Initiative case study: how Pikin to Pikin Tok made a difference $^{511}$

Children

- Teachers who participated in the project reported that the older children showed improved confidence and peer communications skills. Two thirds of young facilitators reported they enjoyed leading classroom activities $(69 \%)$ and most liked expressing their opinions in class (90\%)

- Children attending formal listening groups and informal radio listeners felt encouraged to continue their education after Ebola and developed strong foundations in basic literacy and numeracy

"A schoolboy was academically underperforming, but as he took part in the radio programme listening group, his academic performance improved to the point where he was able to pass the NPSE exam and went on to attend a good secondary school in Kenema district." Teacher, endline evaluation

- During the final evaluation, children showed good recall of the key messages from the radio programmes, such as how to prevent the spread of Ebola or the risks associated with teenage pregnancy. Children were able to link what they had learnt from the broadcasts and apply it to their own lives, such as hand washing to stop the spread of disease, walking in groups to stay safe, or telling friends not to drop out of school

- Most children showed an improved understanding of the risks related to abuse. Children gained knowledge of their rights and built confidence to speak to their parents or other community members about subjects that concerned them

"Children before this time were shy even to talk to their teachers, to talk to their parents, bring up issues or challenges in their communities, but since the intervention of this project, children no longer have fears, neither[are they] timid in that respect. Whatever the issues they have they make sure [they] voice it out to their teachers, to their parents or guardians" Key informant, endline evaluation

- After the radio programmes, children would talk to their peers who had not listened to them about what they had learnt. This aided the spread of knowledge throughout communities

Parents/guardians

- Interviews during the endline evaluation showed that the project influenced changes in attitude towards early childhood education, especially increasing prioritisation of girls' education

- Adult involvement in audio collection helped to develop understanding of the importance of positive parent-child relationships and the harms facing their children

- Almost two thirds of parents interviewed in the endline evaluation agreed that parents listened to the radio programme (64\%), and most liked it (59\%). Parents overwhelmingly felt the radio programme helped their child to learn (77\%), and over half (55\%) discussed the broadcasts with their children. Parents also reported being more aware of their responsibility to keep their children safe

"Most parent (sic) can now admit to us that initially we never knew about the importance of education or early childhood development or how can we even prioritise girl child education." Key informant, endline evaluation

Teachers

- Through listening to the radio programmes with their classes, teachers and head teachers gained increased knowledge of sensitive topics, such as child protection and teenage pregnancy, and confidently talked to children about these problems. After the radio programme, some teachers supported children in creating short dramatisations exploring concerns affecting them

- Teachers increased their use of child friendly teaching methods, learning creative methods for teaching literacy and numeracy

in the world, were not simply beneficiaries of the project but actively participated in creating the programmes. Young journalists identified and captured audio content on important subjects affecting them, their siblings, peers, and neighbours in the wake of the crisis, including the desperation, isolation, and stigma felt by children directly affected by Ebola. No other radio programme in Sierra Leone at that time had children as active participants.

PtPT was continually adapted in response to community feedback. The Ministries of Health, Education, and Social Welfare played a part in the project-for example, by participating in the live panel discussions after each PtPT broadcast. Children were encouraged by trained adult facilitators to phone in and challenge government officials about their concerns, such as lack of enforcement of bylaws on gender based violence.

\section{Expanding the multistakeholder network effectively}

"As an institution we could not do this all by ourselves ... all these sectors helped this project to succeed.... we told them, based on our assessment, that this is a tasking problem that requires us all to come on board to complement the government's effort in moving these sectors forward. We were welcomed and appreciated for this initiative." Former staff member at Pikin-To-Pikin, May 2018

As previously noted, the multistakeholder network that resulted from the Getting Ready for School project needed to expand to introduce the new project effectively (fig 1). Pikin-To-Pikin's collaboration with the Ministry of Health in its Ebola relief efforts continued for the PtPT project, which included health promotion messages. Private sector agencies also became involved through commissioning local Radio Moa and a UK radio production team. That team worked closely with Child to Child and Pikin-To-Pikin to provide key messages and decide the best way to communicate them in order to educate and change perceptionsfor example, of the role of girls in the family and community, and how to mitigate the risks of violence and early pregnancy. Child to Child's network of international experts, experienced in working in diverse settings, also contributed to the redesign.

"This project didn't stop at Pikin-ToPikin, the whole community was involved" Working group participant, May 2018

Stakeholders consistently reported the strong influence of religious leaders in encouraging the acceptance of new social norms during the Ebola crisis. Pikin-To-Pikin collaborated with these religious leaders throughout the course of the project and with community leaders, teachers, children, 
and community members. Together they identified the challenges they were facing and decided how Pikin-To-Pikin might support them, including through the radio programmes. Community sensitisation committees (box 6), established during Getting Ready for School, had an important voice in the project and many problems they raised were aired in the radio programmes. Their feedback helped PikinTo-Pikin constantly to adapt to changing circumstances.

Although Pikin-To-Pikin's work was initially authorised nationally, the strongest and most effective relationships with government were achieved by decentralised multisectoral coordination. PtPT was jointly monitored by Pikin-To-Pikin staff and district ministry representatives. The information collected from their quarterly monitoring visits was used to help adapt the project. Frequent and open conversations enabled Pikin-To-Pikin to respond rapidly, appropriately, and effectively during the crisis. These discussions were supported through various district forums and networks, which were open to all relevant stakeholders. Drawing on existing structures and mechanisms to coordinate and implement the collaborative effort was crucial.

\section{Challenges, limitations, and lessons learnt} Adaptation and innovation-Humanitarian crises require innovative responses to tackle new and rapidly emerging chal- lenges. In responding, donors, governments, and implementing partners must remain adaptable to new ways of working. The Ebola crisis in Sierra Leone clearly called for a collaborative response. Child to Child and Pikin-To-Pikin provided this by building on existing successful multisectoral relationships, and establishing new partnerships. Continuity and transparency of communication ensured that partners could see the value of their contributions. Willingness to innovate and adapt helped to realise the joint vision of partners and enabled them to redesign the project to respond to the changing needs of children.

Monitoring impact-The outcomes, indicators, and targets agreed with the donor for the initial project could no longer remain once the project was redesigned. The uncertainty of the crisis meant it was difficult to agree a revised set for which the grantees could be held accountable. These factors, and the challenges of collecting data during the crisis in a short time, hampered the ability to measure robustly the full impact of PtPT and the extent to which the original goals and objectives had been met. In the absence of a humanitarian crisis, monitoring and evaluation of similar interventions is vital to gain a better understanding of the likely effect. Strong evidence on the influence of mass media on knowledge, attitudes, and behaviour is limited. Any effect is likely to depend on the behaviour change being targeted, the context, the quality of the mass media intervention, and the exposure to the intervention. Evidence from a randomised controlled trial in Burkina Faso showed that mass media alone can change health seeking behaviour, with substantial increases in consultations for children under 5 years old at primary health centres for the leading causes of postneonatal child mortality (malaria, pneumonia, and diarrhoea). ${ }^{16}$ However, substantial decreases in child mortality in both intervention and control groups meant no significant difference in the intervention clusters was seen. Further modelling of these data estimated that deaths in children under 5 had been reduced by an average of $7.1 \%$ a year. ${ }^{17}$ In PtPT, additional activities, such as listening groups, were designed to help reinforce the information broadcast through radio.

Donor involvement-The global community took several months to respond to the Ebola outbreak, which meant that in the early phase, agencies already on the ground had limited resources. Some donors suspended grants, a common practice during a humanitarian crisis, which can lead to serious consequences, especially for local staff reliant on these salaries. Many donors do not understand the need for flexibility and establishing a relationship of trust with agencies that are willing to continue operating despite the risks, and which have established relationships with the authorities and the community. In this case, salaries of all Pikin-To-Pikin's employees

Box 4: Gender considerations within Pikin to Pikin Tok (PtPT)

PtPT's gender responsiveness drew on contextual evidence of the increased vulnerabilities of girls:

- Listening groups and phone ins had a good balance of boys and girls

- Two young journalist groups were made up solely of girls, to ensure attention focused on problems facing girls in these communities

- One of two radio presenters was female

- Female role models discussed their achievements and overcoming challenges in positive sound bites, interviews, and discussion groups

- Female fictional characters were created in radio dramas to further involve girl listeners

- Gender equality messages were integrated throughout the radio programmes. The endline evaluation highlighted that children engaged with the project had positive views about gender and gender equality. Girls noticeably took leading roles in discussions, and this was comfortably accepted by the boys

- Life skills focused on developing girls' self confidence and giving them the authority to make "safe choices." Information was disseminated to girls, their families, and the community about risks, such as gender based violence, early marriage, and teenage pregnancy, and how to overcome them, highlighting the importance of girls' education

- Positive gender ideas were promoted and value placed on girls' safety

- Boys were taught about responsible behaviour to encourage non-violent male identity without sexual risk taking

- The Child Right Act 200712 sets out the legislative framework to protect girls below the age of 18 years from female genital mutilation (FGM) in Sierra Leone. Pikin-To-Pikin carried out advocacy work with parents/guardians to aid the enforcement of community bylaws protecting children from FGM. All soweis (initiators) were invited to a meeting in Kailahun town hall to discuss ending FGM in children. It was also discussed during the PtPT Under the Mango Tree programme with adolescent girls

- Qualitative data collected at the endline evaluation showed positive changes in attitude towards early childhood education, and increased prioritisation of girls' education ${ }^{11}$

"Parents ... in the community [were] just looking at education only meant for boys and not girls. But through this intervention, it has really motivated the parents to send in their children, most especially the girl to school." Key informant, endline evaluation 
Box 5: Recognition for Pikin to Pikin Tok (PtPT)

- Child to Child and Pikin-To-Pikin received a grant of $£ 20000$ in 2016 from The Circle (philanthropic female focused non-government organisation) to enable production of additional radio programmes focusing on adolescent girls as part of the Under the Mango Tree strand - PtPT was selected by the UN Girls' Education Initiative in 2016 as an example of good practice in girls' education ${ }^{5}$

- In 2016, one of PtPT's contributors was recognised in the University of Oxford's vice chancellor's awards for translation of complex medical information into accessible public health messages. The programme featured questions from a 12 year old girl from Kailahun about vaccinations for Ebola, with the aim of supporting any future immunisation campaigns ${ }^{13}$

- A BBC World Service documentary in 2016 focused on PtPT ${ }^{14}$

- Shortlisted for the Bond Innovation Award in $2017^{15}$

- Child to Child won the Social Impact Award at the UK's Asian Voice Charity Awards in 2018, in recognition of their achievements with PtPT

were maintained, and raised to cover the increased cost of basic goods. The donor chose to continue to fund organisations without direct humanitarian experience, but which understood the local context and had strong multisectoral relationships.

Stakeholder readiness and coordination mechanisms subnationally-The original project required significant investment to develop the capability of a range of stakeholders, including children, community sensitisation committees, teachers, and master trainers from the Ministries of Education and Social Welfare. That investment resulted in a strong cadre of committed people ready to respond, and adapt their roles, to the challenges of the redesigned project. Working with district stakeholders, forums, and networks strengthened the multisectoral collaboration and the ability to respond rapidly and appropriately to the changing situation. Frequent communication within and across these networks cemented the effectiveness of both pre-existing and newly established structures. However, working within existing structures was challenging. For example, funds were lacking for monitoring and evaluation by government, which therefore needed to be covered by donors. Money was significantly limited owing to the Ebola crisis and stakeholders already overwhelmed by events were less willing to undertake extra activities without targeted financial incentives. Sufficient financial investment is required for this level of coordination, whether as part of the immediate humanitarian response or for longer term development.

Evolution based on continuous feedback, with children at the heart-The PtPT initiative built on and adapted an existing programme while ensuring relevance to the immediate situation. Dealing with practical problems ensured relevance. This approach was facilitated by regular monitoring and stakeholder feedback, especially from communities and children. Participatory approaches were essential. The Child to Child and Pikin-To-Pikin teams kept children at the heart of the process when redesigning the programme to best respond to the problems facing children. Children involved in the programme gained authority, obtaining experience as journalists and facilitators, and were encouraged by listener groups to challenge adults, including parents and government representatives. They critically assessed their circumstances and how to support and protect each other, and openly discussed subjects normally regarded as taboo or difficult, such as sexual abuse. However, Pikin-To-Pikin reported that one major challenge was the hesitancy of children to participate in listening groups. These groups were unfamiliar, and some of the subjects discussed were difficult, such as gender based violence, stigma, and isolation. Some parents did not allow their children to attend the listening groups, and initially, there was higher attendance from boys. Girls were more commonly prohibited from attending, owing to their increased responsibility for household chores, or because their safety could not be guaranteed on the way to and from the meeting place. The listenership for the programmes was much wider than the listening groups, and another major challenge was providing more children with structured opportunities to deal with the concerns raised. The live panel discussions after each broadcast were one solution. In addition, community sensitisation activities, and children hearing their contemporaries discuss problems, helped to raise awareness about the key messages, change perceptions, and increase girls' participation in the listening groups.

\section{Conclusion}

This case study illustrates how investment in smaller organisations, already operating successfully and which have built relationships of trust with their communities and authorities, can produce results during and after a humanitarian crisis. The PtPT project enabled education to continue when schools were closed, and reached a far larger number of beneficiaries than the original project. The sustained commitment and flexibility of Pikin-To-Pikin, Child to Child, and Comic Relief was beneficial across sectors. This project gave children a voice through the powerful and relatively low cost medium of radio. It ensured that, despite the crisis,

\section{Box 6: Establishment of community sensitisation committees}

Community sensitisation committees comprised 12 members selected for their ability to act as gatekeepers and/or to engage key constituencies within the community. Members included chiefs, women leaders, religious leaders, young people, and teachers. Committees nominated a chairman, a vice chairman, and a secretary, and met monthly, sharing ideas and moving from community to community sensitising parents about the importance of education. Three months after establishment of the committees, punctual enrolment of pupils increased greatly. Parents who had concerns about their children teaching others were reassured by committee members that this advanced the children's public speaking skills and improved their knowledge. Committees identified schools that were not child friendly, and pushed for single sex toilets. They also raised concerns of child protection, teenage pregnancy, and school dropout. The problems thus identified enabled Pikin-To-Pikin to determine where to mobilise support

"Pikin-To-Pikin, while working with social welfare, there was cordiality and collaboration. Everything was discussed. If they went to any community and they became aware of child involvement in bad things they would come and discuss it. Social welfare would take the information seriously and inform other partners what Pikin-To-Pikin had found out in the community.... Everybody had a responsibility to work with Pikin-To-Pikin in the case of any problem, especially in the area that was earmarked for their operation." Department of Social Welfare representative, June 2018 
children remained at the heart of the PtPT project and several later initiatives.

The authors thank all stakeholders involved in making Pikin to Pikin Tok (PtPT) such a huge success, and in particular, the young journalists and Usifu Jalloh (story teller). The authors also thank Regina Bas-Taqi for facilitating the first two working group meetings and Alexia Philips and Helen Walker for their support during data collection. The authors extend their gratitude to all who participated in this case study process, including those who gave up their time to attend the working group meetings (Bai Kamara, Sheku Tarawally, Hannah Conteh, Baimba Syllah, Francis Sahr, Mammy Momoh, Theresa Brima); the multistakeholder dialogue meeting (including Haja Rugiatu, Samuel Margai, Alhassan Jalloh); and the advisory group meeting in London (Sonal Zaveri, Teresa Sguazzin, Christiana Brown, Susan Durston). The authors thank Bella Tristam (formerly of Child to Child), Penny Boreham (UK radio production team), Kabba Kylie and Timothy Sellu (formerly of Pikin-To-Pikin). The authors also thank Rachael Hinton and Joanne McManus for continued technical and editorial support. Pikin to Pikin Tok was funded by Comic Relief's Red Nose 2011 Aid Match Programme in partnership with the UK government's Department for International Development.

Contributors and sources: SB and JvD interpreted the data collected. SB and JVD developed the case study, with inputs from PY, TA, and AS. All authors undertook critical revisions of the manuscript drafts. $P Y$ is responsible for the overall content as guarantor.

Competing interests: We have read and understood the BMJ policy on declaration of interests and declare the following interests: funding from the Partnership for Maternal, Newborn, and Child Health (PMNCH) Secretariat to SB for consultancy fees and travel costs to Sierra Leone; funding from the PMNCH Secretariat to Child to Child for national consultancy fees and related costs for undertaking the case study; employees of Child to Child (PY, JvD) and Pikin-To-Pikin Movement (AS, TA) implementing the project that is the focus of the case study; and attendance at the forthcoming PMNCH Partners' Forum in December 2018 (SB, AS). The views expressed in this article are those of the authors and do not necessarily represent the views, decisions, or policies of the institutions with which they are affiliated.

Provenance and peer review: Commissioned, externally peer reviewed.

This article is part of a series proposed by the WHO Partnership for Maternal, Newborn and Child Health (WHO PMNCH) and commissioned by The BMJ, which peer reviewed, edited, and made the decision to publish the article. Open access fees for the series are funded by WHO PMNCH.

Sarah Barnett, consultant

Jetske van Dijk, development officer ${ }^{2}$
Abdulai Swaray, executive director ${ }^{3}$

Tamba Amara, project officer ${ }^{3}$

Patricia Young, director ${ }^{2}$

${ }^{1}$ SB Consultancy World, Bristol, UK

${ }^{2}$ Child to Child, London, UK

${ }^{3}$ Pikin-To-Pikin Movement, Freetown, Sierra Leone

Correspondence to: PYoung

triciayoung99@gmail.com

\section{(c) (1) OPEN ACCESS}

This is an Open Access article distributed under the terms of the Creative Commons Attribution IGO License (https://creativecommons.org/licenses/ by-nc/3.0/igo/), which permits use, distribution, and reproduction for non-commercial purposes in any medium, provided the original work is properly cited.

\section{Check for updates}

1 UN Office for the Coordination of Humanitarian Affairs. Sierra Leone: Kailahun district profile (3 December 2015). ReliefWeb, 2015. https:// reliefweb.int/report/sierra-leone/sierra-leonekailahun-district-profile-3-december-2015

2 United Nations Regional Information Centre for Western Europe. Ebola kicked out from Kailahun, Sierra Leone. 2014. https://www.unric.org/en/latestun-buzz/29590-ebola-kicked-out-from-kailahun

3 Pryor J. The street child: Ebola orphan report. Street Child, 2015. https://static1.squarespace.com/ static/531748e4e4b035ad0334788c/t/54f47aes e4b0970ed174bbe1/1425308393915/Street+Chi d+Ebola+Orphan+Report+Summary+Version.pdf

4 Wint C. Sierra Leone: UK must commit existing funds to child protection as cases of sex abuse rise. WorldVision UK, 2016. https://www.worldvision. org.uk/news-and-views/latest-news/2016-news/ september/sierra-leone-uk-must-commit-existingfunds-child-protection/

5 Walker D, Tristram B, Pereznieto P, Young T. Childcentred educational radio project in Kailahun district, Sierra Leone. United Nations Girls' Education Initiative, 2016. http://www.childtochild. org.uk/wp-content/uploads/2016/07/CTC_ODIUNGEI-Final.pdf

6 Denny L, Gordon R, Ibrahim A. Teenage pregnancy after Ebola in Sierra Leone: mapping responses, gaps and ongoing challenges. Overseas Development Institute, Secure Livelihood Research Consortium, 2015. https://securelivelihoods.org/wp-content/ uploads/Teenage-Pregnancies-after-Ebola-inSierraLeone_-Mapping-responses-gaps-andongoing-challenges.pdf

7 Risso-Gill I, Finnegan L. Children's Ebola recovery assessment Save the Children, World Vision
International, Plan International, and UNICEF, 2015. https://www.savethechildren.org/content/dam/ global/reports/emergency-humanitarian-response/ ebola-rec-sierraleone.pdf

8 Child to Child. Increasing access, retention and performance in primary education in Sierra Leone. 2014. http://www.childtochild.org.uk/ projects/enhancing-primary-education-kailahunsierra-leon

9 Partnership for Maternal, Newborn \& Child Health. What works and why? Success factors for collaborating across sectors for improved women's, children's and adolescents' health. 2018. http://www.who.int/ pmnch/knowledge/case-studies/en/index3.html

10 Partnership for Maternal, Newborn \& Child Health. Methods guide for country case studies on successful collaboration across sectors for health and sustainable development. 2018. http://www.who.int/pmnch/ knowledge/case-study-methods-guide.pd

11 Institute for Development, Child to Child, Pikin-To-Pikin. Final evaluation of the project. Increasing access, retention and performance in primary education. 2016. http://www.childtochild. org.uk/wp-content/uploads/2017/09/FINALEvaluation-Report-21April2017-Institute-forDevelopment.pdf

12 The Child Right Act. 2007. http://www.sierra-leone. org/Laws/2007-7p.pdf

13 Department of Paediatrics, University of Oxford. D Matthew Snape wins prize for engaging the public. 2016. https://www.paediatrics.ox.ac.uk/news/ matthew-snape-wins-prize-for-engaging-the-public

14 BBC World Service. Radio programme on Pikin to Pikin Tok. 2016. https://www.bbc.co.uk/ programmes/p041psrb

15 Short film on Pikin to Pikin Tok. 2016. https://www. youtube.com/watch?v=ieCOAlhltPY

16 Sarrassat S, Meda N, Badolo H, et al. Effect of a mass radio campaign on family behaviours and child survival in Burkina Faso: a repeated crosssectional, cluster-randomised trial. Lancet Glob Health 2018;6:e330-41. doi:10.1016/S2214 $109 \times(18) 30004-4$

17 Murray J, Head R, Sarrassat S, et al. Modelling the effect of a mass radio campaign on child mortality using facility utilisation data and the Lives Saved Tool (LiST): findings from a cluster randomised trial in Burkina Faso. BMJ Glob Health 2018;3:e000808. doi:10.1136/bmigh-2018-000808

Supplement 1: Main components of Getting Ready for School programme Supplement 2: Timeline of programmes Supplement 3:Methods for developing the case study

See www.bmj.com/multisectoralcollaboration for other articles in the series 